\title{
Prevalence of Cryptosporidial Oocysts in Soil of Recreational Parks in Abuja, Nigeria
}

\author{
Idowu Oluwabukola Olufemi', Otalu Otalu Jr. ${ }^{*}$, Mohammed Bello', Idris Alao Lawal', \\ Jacob Kwada Pajhi Kwaga ${ }^{1}$ \\ ${ }^{1}$ Department of Veterinary Public Health and Preventive Medicine, Faculty of Veterinary Medicine, Ahmadu \\ Bello University, Zaria, Nigeria \\ ${ }^{2}$ Department of Veterinary Parasitology and Entomology, Faculty of Veterinary Medicine, Ahmadu Bello \\ University, Zaria, Nigeria \\ Email: *otalu_202@yahoo.com
}

Received 29 September 2014; revised 20 October 2014; accepted 19 November 2014

Copyright (C) 2014 by authors and Scientific Research Publishing Inc.

This work is licensed under the Creative Commons Attribution International License (CC BY).

http://creativecommons.org/licenses/by/4.0/

(c) (i) Open Access

\begin{abstract}
Contamination of soil with cryptosporidial oocysts poses a great health risk to people especially in individuals who are immune-compromised. Exposure to contaminated soil can cause diarrhoea in humans especially in children who play around the parks and may not wash their hands before handling food. The prevalence of cryptosporidial oocyst in soils of 4 recreational parks in Abuja, Nigeria was investigated. Four hundred soil samples were collected from various locations within the recreational parks and examined for the presence of cryptosporidial oocyst using modified acid fast staining technique. In nine (2.3\%) of the samples, 8 were from park $A$ and 1 was from park $B$ contained cryptosporidial oocyst. There was significant association $\left(\chi^{2}=20.1 ; \mathrm{df}=2\right.$; $\mathbf{p}=$ 0.00004) between prevalence of Cryptosporidium oocysts and level of hygiene of the parks. It was concluded that soil in recreational parks may be a source of infection with Cryptosporidium oocysts.
\end{abstract}

\section{Keywords}

Cryptosporidial Oocyst, Recreational Parks, Abuja, Health Risk

\section{Introduction}

Cryptosporidium, a zoonotic coccidian protozoan parasite that has gained significant attention in the last 20 years as a clinically important human and animal pathogen [1] [2] is one of the most common aetiological agents

${ }^{*}$ Corresponding author.

How to cite this paper: Olufemi, I.O., Otalu Jr., O., Bello, M., Lawal, I.A. and Kwaga, J.K.P. (2014) Prevalence of Cryptosporidial Oocysts in Soil of Recreational Parks in Abuja, Nigeria. Open Journal of Medical Microbiology, 4, $224-227$.

http://dx.doi.org/10.4236/ojmm.2014.44024 
of gastroenteritis and diarrhoea in several animal species especially calves, lambs and man [3] [4]. Cryptosporidiosis is considered one of the most prevalent parasitic infections in domesticated caged and wild birds including ducks, canaries, chickens, parrots and domestic geese from Asia, Australia, Europe, North America and North Africa [5]-[7]. Many species of Cryptosporidium infect humans and a wide range of animals; however, Cryptosporidium parvum is the most important species causing disease in humans [8]. Cryptosporidium oocysts are able to move through various soil types and resist environmental pressures such as temperature and $\mathrm{pH}$, indicating its potential to contaminate and survive in the environment [9].

Contaminated water and food are known sources of infection among international travellers and water-borne outbreaks have been reported in North-America and Europe [10]. The parasite is transmitted from person to person through ingestion of contaminated food or drinking water and water used for recreational purposes, from animal to person, or by contact with environmental surfaces contaminated with faeces [11]. The public health importance of cryptosporidiosis has not been widely reported in Nigeria. This can be attributed to the non-routine screening for Cryptosporidium oocyst in stools of diarrhoeal patients in health institutions [12]. Kwaga et al. [13] reported a prevalence rate of $21 \%$ of Cryptosporidium in patients with diarrhoea in Zaria and further reported the prevalence of $0.66 \%$ Cryptosporidium in calves and $15.7 \%$ in piglets in some parts of Kaduna state [14]. Ayeni et al. [15] reported in Ile-Ife the prevalence of cryptosporidial oocysts of 32.6\%, 4.2\%, $12.0 \%$ and $7.6 \%$ among pigs, goats, sheep and cattle respectively. These prevalence rates found in man and animals in the face of poor hygiene and animal husbandry give room for the contamination of soil and water with Cryptosporidium contaminated faeces. In some areas in Nigeria where hygiene is poor, the detection of Cryptosporidium in soil may have health implications. The present study was therefore conducted to determine the status of cryptosporidial oocysts in soil in Abuja recreational parks.

\section{Materials and Methods}

\subsection{Sample Collection}

The study was conducted between September 2010 and February, 2011. Samples were collected on a weekly basis from four parks in Abuja and a total of 400 samples (100 from each of the 4 recreational parks) using a clean garden trowel.

\subsection{Analysis of Samples}

Ten grams of each soil sample was mixed with $100 \mathrm{mls}$ of $10 \%$ formol saline in a universal bottle and was sieved through cotton gauze and poured using a funnel into a centrifuge tube. Ten (10) mls of diethylether was added to the filtrate and thoroughly mixed. The suspension was centrifuged at $5000 \mathrm{rpm}$ for 10 minutes using an MS centrifuge, the supernatant was decanted and a smear was made from the sediment on a microscope slide and air-dried. The smear was fixed for 3 minutes with 3\% hydrochloric acid-methanol and flooded with 1\% aqueous safranin, heated over a Bunsen flame for 1 minute, and the slide was then flooded with water and air-dried. It was counter-stained with $1 \%$ methylene blue for 1 min followed by washing with buffered distilled water. The slides were air dried and the prepared slides were examined by light microscope at $40 \times$ objective under a bright field.

\subsection{Level of Hygiene as Used in the Study}

In this study, the index for determination of the level of hygiene was based on the level of sanitation and beautification of the environment. The different levels as used in the study are enumerated below:

$\mathrm{LH}=1$ (low): when the environment is untidy and no structured pattern of waste collection with heaps of refuse and wastes littering the whole place.

$\mathrm{LH}=2$ (moderate): same as $\mathrm{LH}=1$ but there is a defined area for waste collection.

$\mathrm{LH}=3$ (high): there is no littering of wastes within the sites, there is availability of waste disposal bins and collected wastes are either burnt or buried.

\subsection{Data Analysis}

Chi-square was used to analyze the data for associations with variables and values of $\mathrm{p}<0.05$ considered significant. 


\section{Results}

Table 1 shows the percentage prevalence of cryptosporidial oocysts in soil samples from each of the four recreational parks. Among the 400 soil samples examined, 9 (2.3\%) contained Cryptosporidium oocysts. Park A recorded the highest prevalence of $8.0 \%$, while park B had $1.0 \%$ prevalence. However, no cryptosporidial oocyst was detected in samples collected at parks $C$ and $D$. There was a significant association $\left(\chi^{2}=20.35 ; \mathrm{df}=3 ; \mathrm{p}=\right.$ 0.0001 ) between the prevalence of cryptosporidial oocysts in the soil samples and the four recreational parks.

Prevalence of Cryptosporidium oocysts according to level of hygiene is shown in Table 2. The highest prevalence (8\%) was in parks of moderate level of hygiene, followed by low level $(0.5 \%)$. No Cryptosporidium oocyst was detected in parks of high level of hygiene. There was significant association $\left(\chi^{2}=20.1 ; \mathrm{df}=2 ; \mathrm{p}=\right.$ 0.00004) between prevalence of Cryptosporidium oocysts and level of hygiene of the parks.

\section{Discussion}

The prevalence of cryptosporidial oocysts in parks as observed in this study, though relatively low, is of importance considering the fact that Cryptosporidium can cause illness especially in immune-compromised individuals. There is increasing concern that foods, particularly those of animal origin, may play a role in the transmission of Cryptosporidium parvum to humans. Contaminated soil may also poses a great health risk to humans as meat sold for consumption may be in contact with soil and this may help in the transfer of the oocysts to humans. The low detection rate of cryptosporidial oocysts may not be unconnected to technique employed as pathogen like Cryptosporidium that can occur in low numbers requires a more sensitive method for isolation.

The highest prevalence of cryptosporidial oocysts in park A may not be unconnected with the layout of the park as there is a bridge and running water across the park which may help in the dispersion of Cryptosporidium oocysts within the area especially during severe flooding. Oocysts may be carried along such water bodies. The prevalence in park B though relatively low may be because of the activities and location of zoo in the park. It was not surprising that no Cryptosporidium oocyst was detected in park $\mathrm{C}$ which was the biggest and in terms of hygiene and sanitation the neatest of all the parks. In contrast, park D that was almost the opposite of park A in terms of level of hygiene also recorded no Cryptosporidium oocyst. This may be that the park was not contaminated with Cryptosporidium oocyst or that the soil samples were not taken from Cryptosporidium contaminated areas. It may also mean that number of oocysts present was so low that the technique used failed to detect a positive sample.

Table 1. Cryptosporidium oocysts in recreational parks soil samples in Abuja.

\begin{tabular}{ccc}
\hline Parks & No. of soil samples examined & No. (\%) positive \\
\hline A & 100 & $8(8)$ \\
B & 100 & $1(1)$ \\
C & 100 & $0(0)$ \\
D & 100 & $0(0)$ \\
Total & 400 & $9(2.3)$
\end{tabular}

$\chi^{2}=20.35 ; \mathrm{df}=3 ; \mathrm{p}=0.0001$.

Table 2. Prevalence of Cryptosporidium oocysts in soil samples according to level of hygiene in parks within Abuja metropolis.

\begin{tabular}{ccc}
\hline Level of hygiene & No. of samples examined (\%) & Positive samples (\%) \\
\hline Low & $200(50)$ & $1(0.5)$ \\
Moderate & $100(25)$ & $8(8)$ \\
High & $100(25)$ & $0(0)$ \\
Total & $400(100)$ & $9(2.3)$ \\
\hline
\end{tabular}

$\chi^{2}=20.1 ; \mathrm{df}=2 ; \mathrm{p}=0.00004$. 
Though no Cryptosporidium oocyst was detected in park of high level of hygiene, the highest prevalence of Cryptosporidium oocyst in parks moderately rated in terms of level of hygiene may be because of increased activity within the parks and a possibility of mechanical transfer of oocysts from one location to another. The occurrence of Cryptosporidium in the soil within the recreational parks, especially in areas where children play, should be a source of concern to public health officials and regulators of these recreational parks as contaminated soils may be a source of infection with Cryptosporidium oocyst. Also, animal fecal waste applied as manure to soils should be effectively managed to minimize environmental and public health risk.

\section{References}

[1] Guerrant, R.L. (1997) Cryptosporidiosis: An Emerging, Highly Infectious Threat. Emerging Infectious Diseases, 3, 5156. http://dx.doi.org/10.3201/eid0301.970106

[2] Caccio, S., Pinter, E., Faitimi, R., Mezzaro, I. and Pozio, E. (2002). Human Infection with Cryptosporidium felis; Case Report and Literature Review. Emerging Infectious Diseases, 81, 85-86. http://dx.doi.org/10.3201/eid0801.010269

[3] Tzipori, S.R., Campbell, I. and Angus K.W. (1982) The Therapeutic Effect of 16 Antimicrobial Agents on Cryptosporidial Infection in Mice. Australian Journal of Experimental Biology and Medical Science, 60, 187-190. http://dx.doi.org/10.1038/icb.1982.20

[4] Current, W.L. (1985) Cryptosporidiosis in the Acquired Immunedeficiency Syndrome. A Case Report. Journal of American Veterinary Medical Association, 187, 1334-1338.

[5] Hoerr, F.J., Current, W.L. and Haynes, T.B. (1985) Fatal Cryptosporidiosis in Quail. Avian Diseases, 30, 421-425. http://dx.doi.org/10.2307/1590550

[6] Godwin, M.A. (1989) Cryptosporidiosis in Birds. A Review. Avian Pathology, 18, 365-384. http://dx.doi.org/10.1080/03079458908418612

[7] Lindsay, D.S. and Blagburn, B.L. (1990). Cryptosporidiosis in Birds. In: Dubey, J.P., Speer, C.A., and Fayer, R., Eds., Cryptosporidiosis in Man and Animals, CRC Press, Boca Raton, 133-148.

[8] Current, W.L. (1987) Cryptosporidium: Its Biology and Potential for Environmental Transmission. Journal of Environmental Health, 17, 21-51.

[9] Mawdsley, J.L., Brooks, A.E. and Merry, R.J. (1996) Movement of the Protozoan Pathogen Cryptosporidium parvum through Three Contrasting Soil Types. Biology and Fertility of Soils, 21, 30-36. http://dx.doi.org/10.1007/BF00335990

[10] O’Donoghue, P.J. (1995) Cryptosporidium and Cryptosporidiosis in Man and Animals. International Journal of Parasitology, 25, 139-195. http://dx.doi.org/10.1016/0020-7519(94)E0059-V

[11] Mackenzie, W.R., Hoxie, N.J., Proctor, M.E., Gradus, M.S., Blair, K.A., Peterson, D.E., Kazmierczak, J.J., Addiass, D.G., Fox, K.R., Rose, J.B. and Davis, J.P. (1994) A Massive Outbreak in Milwaukee of Cryptosporidium Infection Transmitted through the Public Water Supply. New England Journal of Medicine, 331, 161-167. http://dx.doi.org/10.1056/NEJM199407213310304

[12] Mbanugo, J.I. and Agu, V.C. (2006) Prevalence of Cryptosporidium parvum Infections in Children, Aged 0-15 Years, in Anambra State, Nigeria. Nigerian Journal of Parasitology, 26, 1-5. http://dx.doi.org/10.4314/njpar.v26i1.37720

[13] Kwaga, J.K., Umoh, J.U. and Odoba, M.B. (1988) Cryptosporidium Infection in Humans with Gastroenteritis in Zaria, Nigeria. Epidemiology International, 101, 93-97.

[14] Kwaga, J.K.P., Uzor, E.I. and Umoh, J.U. (1988). Cryptosporidium Infections in Calves and Piglet in Some Parts of Kaduna, Nigeria. Zariya Veterinarian, 3, 86-89.

[15] Ayeni, A.O., Olubunmi, P.A. and Abe, J.O. (1985) The Occurrence of Cryptosporidium in Faeces of Livestock in IleIfe, Nigeria. Tropical Veterinarian, 3, 96-100. 
Scientific Research Publishing (SCIRP) is one of the largest Open Access journal publishers. It is currently publishing more than 200 open access, online, peer-reviewed journals covering a wide range of academic disciplines. SCIRP serves the worldwide academic communities and contributes to the progress and application of science with its publication.

Other selected journals from SCIRP are listed as below. Submit your manuscript to us via either submit@scirp.org or Online Submission Portal.
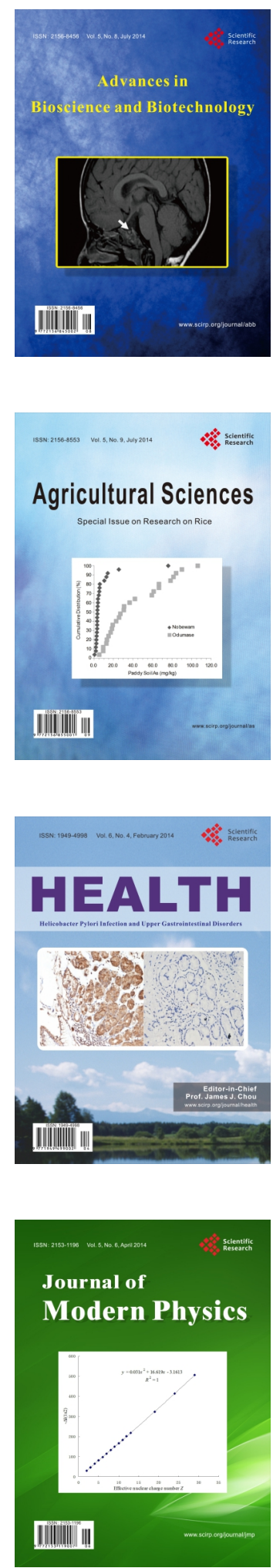
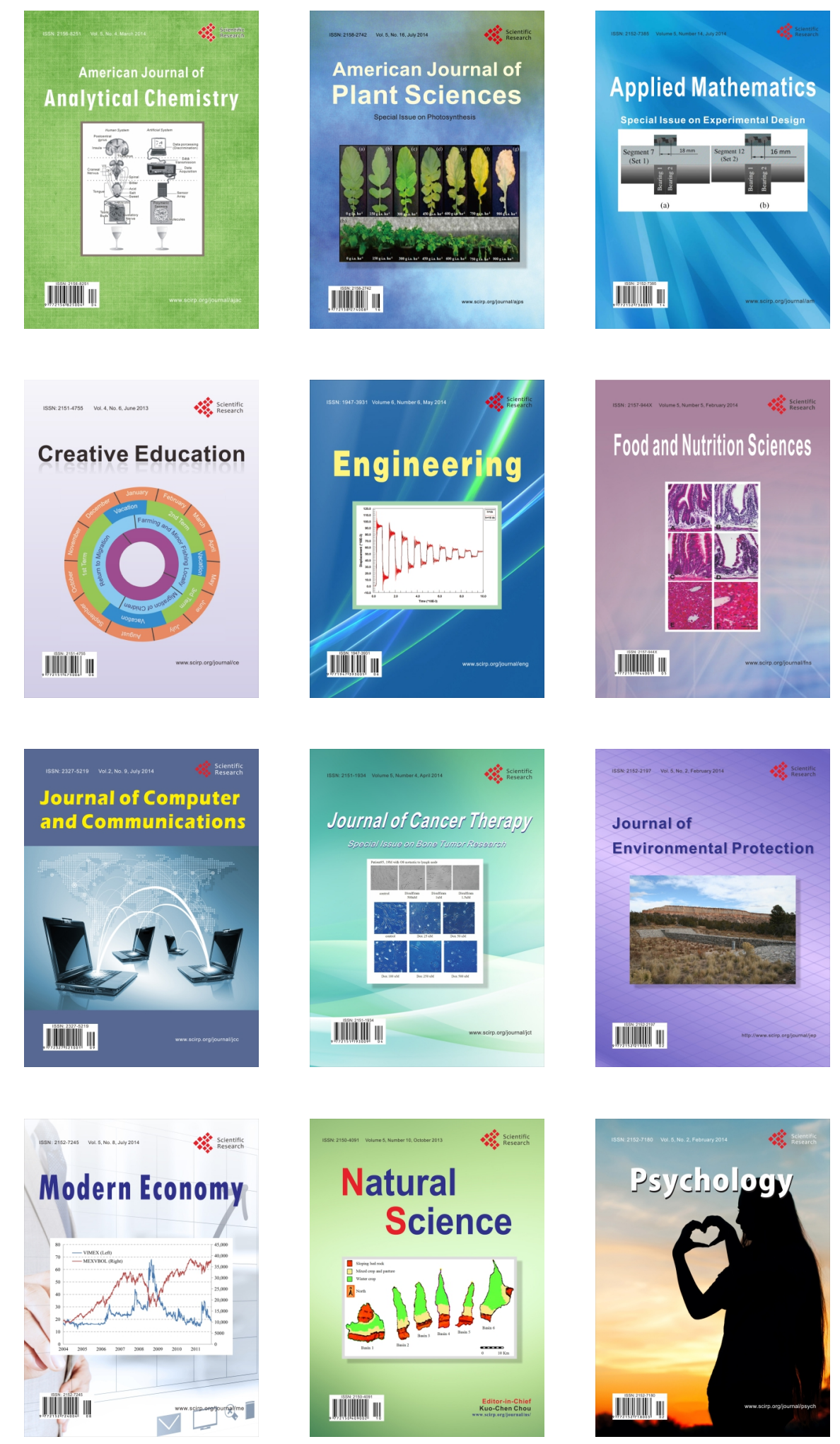